\title{
Erythrocyte phosphoglucomutase activity of bipolar I patients currently using lithium or carbamazepine
}

M. Montero-Lomelí ${ }^{1}$,

D. Galvão ${ }^{1}$, B.B. Morais ${ }^{1}$ and A.E. Nardi ${ }^{2}$
${ }^{1}$ Programa de Biologia Molecular e Biotecnologia, Instituto de Bioquímica Médica, ${ }^{2}$ Laboratório de Pânico e Respiração, Instituto de Psiquiatria, Universidade Federal do Rio de Janeiro, Rio de Janeiro, RJ, Brasil

\section{Correspondence}

M. Montero-Lomelí

Instituto de Bioquímica Médica

CCS, UFRJ

Bloco D, Subsolo, Sala 11

21940-590 Rio de Janeiro, RJ

Brasil

Fax: +55-21-2561-2936

E-mail: montero@bioqmed.ufrj.br

Research supported by a FAPERJ grant to M. Montero-Lomelí, and by CNPq grants to M. Montero-Lomelí and A.E. Nardi. D. Galvão was the recipient of an undergraduate fellowship from CNPq.

Received March 9, 2006 Accepted October 9, 2006

\begin{abstract}
Lithium has been used for the last five decades to treat bipolar disorder, but the molecular basis of its therapeutic effect is unknown. Phosphoglucomutase is a key enzyme in the metabolism of glycogen. In yeast, rabbit and human HEK293 cells, it is inhibited by lithium in the therapeutic concentration range. We measured the phosphoglucomutase activity in erythrocytes and the inhibitor constant for lithium in a population of healthy subjects and compared them to those of bipolar patients treated with lithium or carbamazepine. The specific activity of phosphoglucomutase measured in vitro in erythrocytes from control subjects presented a normal distribution, with the difference between the lowest and the highest activity being approximately 2-fold (0.53-1.10 nmol mg Hb-1 $\left.\mathrm{min}^{-1}\right)$. Comparison of phosphoglucomutase activity in untreated bipolar patients and control subjects showed no significant difference, whereas comparison between bipolar patients treated with carbamazepine or lithium revealed significantly lower mean values in patients treated with carbamazepine (747.3 \pm 27.6 vs $879.5 \pm 35.9$ pmol mg Hb$~^{-1} \mathrm{~min}^{-1}$, respectively). When we studied the concentration of lithium needed to inhibit phosphoglucomutase activity by $50 \%$, a bimodal distribution among the population tested was obtained. The concentration of $\mathrm{LiCl}$ needed to inhibit phosphoglucomutase activity by $50 \%$ was 0.35 to $1.8 \mathrm{mM}$ in one group of subjects and in the other it was 3 to $4 \mathrm{mM}$. These results suggest that phosphoglucomutase activity may be significant in patients with bipolar disorder treated with lithium and carbamazepine.
\end{abstract}

\section{Introduction}

An important strategy for investigating the molecular basis of bipolar disorder is to study the effects of the different drugs used for treatment on enzyme activity. Lithium has been used extensively for the treatment of bipolar disorder over the last 45 years (1).
Key words

- Phosphoglucomutase

- Lithium

- Carbamazepine

- Bipolar disorder 
and inhibition leads to severe defects in development in Xenopus laevis embryos and in Dictyostelium discoideum (2-6). Some of the enzymes inhibited by lithium share the structural motif Asp-Pro-(Ile/Leu)-Asp-Gly/ Ser)-Thr/Ser that is responsible for lithium binding, such as inositol monophosphatase, inositol polyphosphate 1-phosphatase, fructose 1,6-biphosphate phosphatase, and biphosphate nucleotidase (7).

It has been recently shown that phosphoglucomutase is also inhibited by lithium in different species such as yeast (8) rats (9) and human HEK293 cells (8). We believe that the relevance of phosphoglucomutase activity in the manifestation of bipolar disorder and in the action of lithium deserves study. Phosphoglucomutase is an enzyme that is central to carbohydrate metabolism and protein glycosylation. It is responsible for the reversible interconversion of glucose 1-phosphate (Glu 1-P) to glucose 6-phosphate (Glu 6-P), both of which are key intermediates in the synthesis and breakdown of glycogen and in galactose metabolism. It is also important for the formation of UDPglucose which is an essential intermediary metabolite in protein glycosylation. Inhibition of phosphoglucomutase by lithium in yeast cells has drastic effects on carbohydrate metabolism. During glucose metabolism lithium reduces the steady-state levels of UDP-glucose, resulting in a defect of glycogen and trehalose biosynthesis, while galactose metabolism is inhibited, leading to galactosemia, accumulation of galactose-1P and Glu 1-P and inhibition of fermentation $(8,10)$. A recent report has shown that lithium treatment up-regulates phosphoglucomutase activity in various tissues of the rat and in bipolar patients, even though lithium inhibits phosphoglucomutase activity in vitro (11).

In the present study, we measured phosphoglucomutase activity in human erythrocytes and determined whether this activity is altered in patients with bipolar disorder treated or not with lithium or carbamazepine.

\section{Patients, Material and Methods}

\section{Subject selection}

Participants were men and women aged 18 to 60 years. Patients with bipolar disorder I (BPI) were classified according to the criteria of the Diagnostic and Statistical Manual of Mental Disorders, also known as the DSMIV-tr (12). BPI is characterized by one or more manic or mixed episodes, usually accompanied by major depressive episodes $(12,13)$. Patients who met DSM-IV criteria for other mood disorders were excluded. Patients were randomly recruited from a sample of 211 BPI patients currently receiving assistance in the inpatient unit of the Institute of Psychiatry, Federal University of Rio de Janeiro. We selected the BPI patients who had been taking lithium or carbamazepine for more than one year but had recovered from a recent manic episode and were ready to leave the inpatient clinic. Blood was collected into Vacuette ${ }^{\circledR}$ EDTA tubes which contain $8 \%$ liquid EDTA solution, when the patient left the inpatient ward. Women of childbearing potential were included if they were utilizing an effective method of birth control. The study was approved by the Ethics Review Board of the Institute of Psychiatry and all patients gave written informed consent to participate.

Patients who had been receiving lithium $(\mathrm{N}=21$; mean age: $41.2 \pm 13.0$ years; 8 males and 13 females) or carbamazepine $(\mathrm{N}$ $=17$; mean age: $44.5 \pm 10.3$ years; 7 males and 10 females) for at least one year were selected. Two of the lithium patients were on lithium monotherapy, while the others were also receiving diazepam $(\mathrm{N}=6)$; diazepam and olanzapine $(\mathrm{N}=1)$; diazepam, haloperidol and promethazine $(\mathrm{N}=5)$; diazepam and imipramine $(\mathrm{N}=2)$; haloperidol $(\mathrm{N}=1)$; haloperidol and olanzapine $(\mathrm{N}=2)$, or valproic acid, haloperidol and chlorpromazine $(\mathrm{N}=2)$. Serum lithium levels ranged from 0.40 to $1.10 \mathrm{mEq} / \mathrm{L}$, with a mean $\pm \mathrm{SD}$ 
of $0.725 \pm 0.159 \mathrm{mEq} / \mathrm{L}$. Carbamazepinetreated patients were on monotherapy. Control subjects were volunteers $(\mathrm{N}=22 ; 6$ males and 16 females; mean age: $31.0 \pm 11.2$ years) who declared that they had never sought psychiatric help. They were also interviewed by two psychiatrists using the Structured Clinical Interview (14) for DSMIV. The age difference between patients and controls was not significant and the phosphoglucomutase-specific activity did not correlate with the age of the subjects under study (data not shown).

\section{Cell preparation}

Blood samples were collected into EDTAcontaining tubes and immediately centrifuged at 3,000 rpm for $10 \mathrm{~min}$. The plasma and leukocyte layers were discarded. Three volumes of $160 \mathrm{mM} \mathrm{KCl}$ were added to erythrocytes and the preparation was centrifuged three times for $10 \mathrm{~min}$ each at 2,000 rpm. After the final centrifugation the red cell layer was resuspended in $0.5 \mathrm{~mL} 160$ $\mathrm{mM} \mathrm{KCl}$ and kept at $-70^{\circ} \mathrm{C}$ until use.

\section{Biochemical methods}

Phosphoglucomutase activity was measured using a coupled system (14). Briefly, lysed erythrocytes $(0.050-0.090 \mathrm{mg}$ hemoglobin) were incubated at $37^{\circ} \mathrm{C}$ in $250 \mu \mathrm{L}$ buffer containing $50 \mathrm{mM}$ Tris- $\mathrm{HCl}, \mathrm{pH} 7.5$, $0.5 \mathrm{mM} \mathrm{NAD}^{+}, 0.025 \mathrm{mM}$ glucose 1,6-diphosphate, 2 units $/ \mathrm{mL}$ recombinant Leuconostoc mesenteroides glucose-6-phosphate dehydrogenase, $1.5 \mathrm{mM} \mathrm{MgCl}_{2}$, and $1.0 \mathrm{mM}$ EDTA, unless otherwise stated. The reaction was started by the addition of $4 \mathrm{mM}$ Glu 1-P, and NADH formation was monitored at $340 \mathrm{~nm}$. Phosphoglucomutase activity is reported as pmol Glu 6-P mg $\mathrm{Hb}^{-1} \mathrm{~min}^{-1}$. Hemoglobin concentration was determined by the cyanmethemoglobin method (15). The concentration of lithium that resulted in $50 \%$ inhibition of maximal activity (termed the
$\mathrm{IC}_{50}$ ) was determined by measuring phosphoglucomutase activity as described above in the presence of increasing concentrations of lithium $(0,0.3,0.6,0.9,1.2$, and $3.0 \mathrm{mM})$. The inhibitor constant or Ki was determined by measuring phosphoglucomutase activity as described above in the presence of 0.1, 1.0 and $10 \mathrm{mM} \mathrm{MgCl}$ and increasing concentrations of $\mathrm{LiCl}$. The $\mathrm{Ki}$ was determined by plotting the results in a Dixon's plot. The $\mathrm{Ki}$ of $\mathrm{Li}^{+}$for yeast and human HEK293 cell phosphoglucomutase was determined earlier by Masuda et al. (8).

To test whether erythrocyte phosphoglucomutase is inhibited by carbamazepine, phosphoglucomutase activity was assayed as described above in the presence of varying concentrations of carbamazepine (10 to $500 \mu \mathrm{M})$. The therapeutic range for the steady-state plasma concentration of carbamazepine generally lies between 4 and 10 $\mu \mathrm{g} / \mathrm{mL}(10-40 \mu \mathrm{M})$.

\section{Results}

\section{Erythrocyte phosphoglucomutase activity}

When erythrocyte phosphoglucomutase was incubated with increasing concentrations of $\mathrm{LiCl}$ in a medium containing 0.1 , 1.0 , or $10 \mathrm{mM} \mathrm{Mg}{ }^{2+}$ a typical competitive inhibition result was obtained, with a calculated apparent $\mathrm{Ki}$ for lithium of approximately $800 \mu \mathrm{M}$ (data not shown), confirming the report of Masuda et al. (8). This indicates that phosphoglucomutase is inhibited by about $50 \%$ within the therapeutic concentration range of lithium (0.4 to 1.0 $\mathrm{mEq} / \mathrm{L})$. The erythrocyte phosphoglucomutase-specific activity of control subjects $(\mathrm{N}$ $=22)$ and lithium-treated patients $(\mathrm{N}=21)$ is reported in Figure 1A and B, respectively. The specific activity ranged from 530 to 1100 pmol mg Hb${ }^{-1} \mathrm{~min}^{-1}$ in control subjects and from 600 to $1300 \mathrm{pmol} \mathrm{mg} \mathrm{Hb}^{-1} \mathrm{~min}^{-1}$ in lithium-treated subjects, showing an approximate 2-fold range of minimum- and maxi- 
Figure 1. Frequency distribution of phosphoglucomutase-specific activity in control subjects and bipolar I patients. Phosphoglucomutase (PGM) activity was measured in lysed erythrocytes from control healthy volunteers $(A ; N=22)$ and from lithiumtreated patients $(B ; N=21)$. Data are the average of three replicates for each individual. Values are normally distributed according to the Shapiro-Wilk test performed at $\mathrm{P}=0.05$ (values obtained were: $\mathrm{W}=0.95732, \mathrm{P}=$ 0.56969 for control group, and $\mathrm{W}=0.89938, \mathrm{P}=0.10989$ for lithium-treated groups).

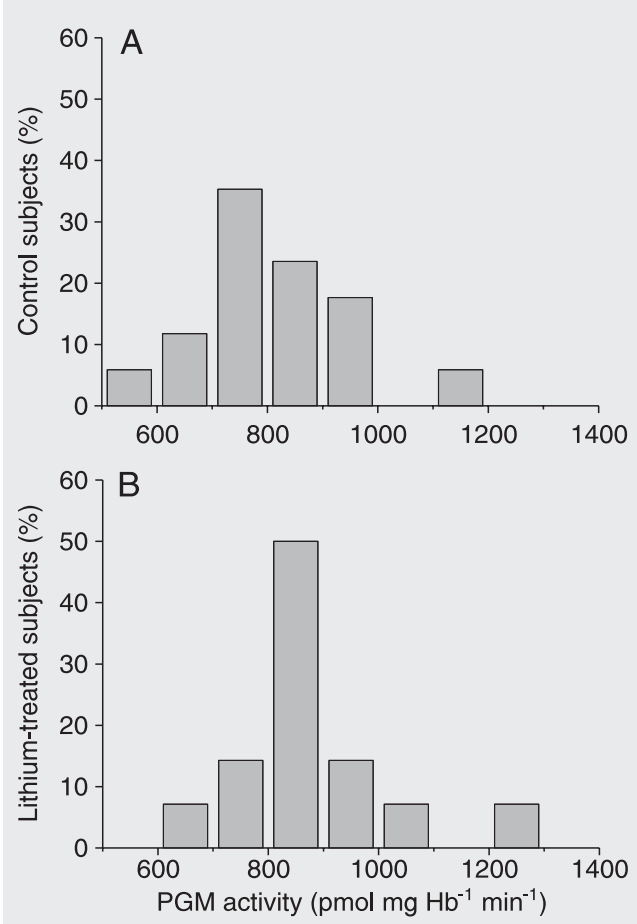

Table 1. Phosphoglucomutase-specific activity ( $\mathrm{pmol} \mathrm{mg} \mathrm{Hb} \mathrm{m} \mathrm{min}^{-1}$ ) in erythrocytes and inhibition by lithium $\left(\mathrm{IC}_{50}, \mathrm{mM}\right)$.

\begin{tabular}{lcc}
\hline & $\begin{array}{c}\text { Phosphoglucomutase activity } \\
\left(\mathrm{pmol} \mathrm{mg} \mathrm{Hb} \mathrm{min}^{-1}\right)\end{array}$ & $\begin{array}{c}\text { Lithium } \\
\mathrm{IC} \mathrm{C}_{50}(\mathrm{mM})\end{array}$ \\
\hline Control $(\mathrm{N}=22)$ & $800.6 \pm 33.3$ & $1.44 \pm 0.34$ \\
Lithium-treated subjects $(\mathrm{N}=21)$ & $879.5 \pm 35.9$ & $1.52 \pm 0.36$ \\
Carbamazepine-treated subjects $(\mathrm{N}=17)$ & $747.3 \pm 27.6$ & $\mathrm{ND}$ \\
\hline
\end{tabular}

Data are reported as means \pm SEM. Although the mean phosphoglucomutase-specific activities were significantly different between the three groups $(P=0.02$, one-way ANOVA), the post hoc Tukey test indicated that only the difference between lithiumand carbamazepine-treated subjects was significant. ND $=$ not determined. mal-specific activity in each group (Figure 1). Shapiro-Wilk test performed at $\mathrm{P}=0.05$ showed evidence that phosphoglucomutase activity values measured for both control and lithium-treated groups are normally distributed. The mean \pm SEM activity for control subjects was not significantly different from that of patients receiving lithium (800.6 \pm 33.3 and $879.5 \pm 35.9 \mathrm{pmol} \mathrm{mg} \mathrm{Hb}^{-1} \mathrm{~min}^{-1}$, respectively; Table 1).

\section{Phosphoglucomutase activity in lithium- and} carbamazepine-treated patients

A recent report showed that, although activity is inhibited in vitro by lithium, leukocyte phosphoglucomutase activity from a group of seven patients treated with lithium is increased in relation to healthy individuals (11). In our patients, a larger group, erythrocyte phosphoglucomutase activity was not significantly different from normal. In both cases it would have been better to analyze subjects before and after treatment. However, it was difficult for us to find a bipolar I patient that had been not medicated. Since we lacked this control we decided to test phosphoglucomutase activity in erythrocytes from patients treated with carbamazepine. We first assayed erythrocyte phosphoglucomutase activity in vitro in the presence of carbamazepine in order to test if carbamazepine modulates the activity of the enzyme. The results showed that carbamazepine does not alter phosphoglucomutase activity (data
Figure 2. Inhibition of phosphoglucomutase activity by lithium. $A$, The concentration of lithium needed for $50 \%$ inhibition of phosphoglucomutase activity $\left(\mathrm{IC}_{50}\right)$ was determined in three replicates from control $(\mathrm{N}=22$, open bars) and lithium-treated subjects ( $N=21$, filled bars). A frequency distribution histogram is shown. $B, I_{50}$ determined in lithiumtreated subjects was plotted as a function of lithemia at the time the blood samples were collected.

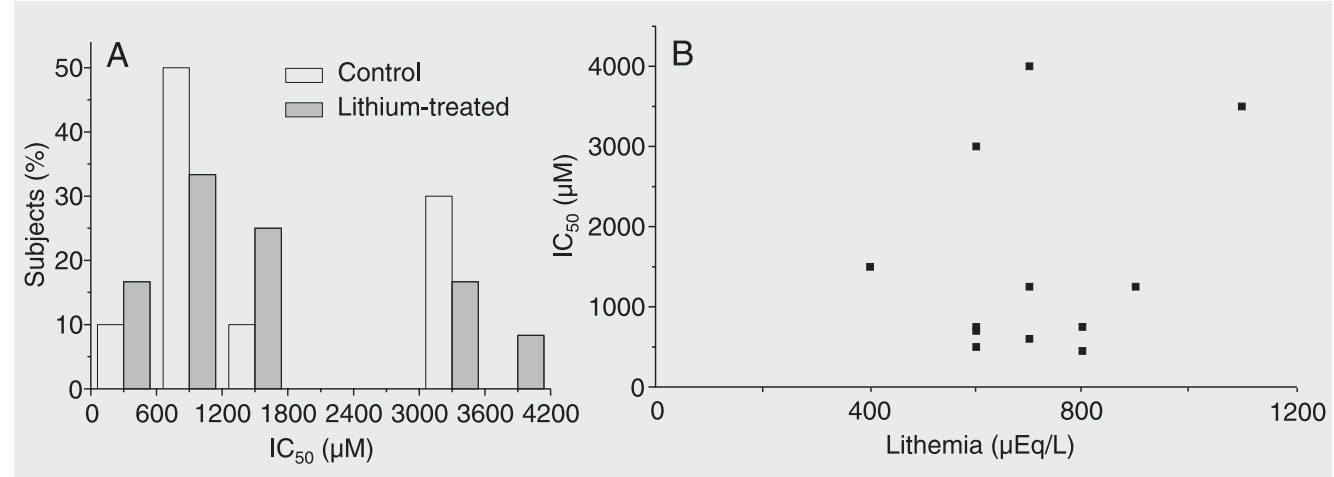


not shown). Next we compared phosphoglucomutase activity between lithium-treated $(\mathrm{N}=21)$ and carbamazepine-treated subjects $(\mathrm{N}=17)$ (Table 1). Carbamazepinetreated patients had a lower erythrocyte phosphoglucomutase activity $(747.3 \pm 27.6$ pmol $\mathrm{mg} \mathrm{Hb}^{-1} \mathrm{~min}^{-1}$ ) than subjects treated with lithium $\left(879.5 \pm 35.9 \mathrm{pmol} \mathrm{mg} \mathrm{Hb}^{-1}\right.$ $\left.\mathrm{min}^{-1}\right)$. This difference was statistically significant ( $\mathrm{P}=0.02$, one-way ANOVA). It is possible that there is a difference between erythrocyte and leukocyte phosphoglucomutase.

\section{Distribution of lithium's $\left(\mathrm{IC}_{50}\right)$ on phosphoglucomutase activity}

An important characteristic of bipolar I patients is that lithium treatment is not always effective. Thus, we examined the distribution of the concentration of lithium needed to inhibit erythrocyte phosphoglucomutase activity by $50 \%\left(\mathrm{IC}_{50}\right)$, comparing control subjects (Figure 2A, open bars) with lithium-treated patients (Figure 2A, filled bars; Table 1). In this experiment, phosphoglucomutase activity was measured in the presence of $0.1 \mathrm{mM} \mathrm{Mg}^{2+}$ since it has been shown that the intracellular free $\mathrm{Mg}^{2+}$ level is approximately $0.16 \mathrm{mM}$ (11). The $\mathrm{IC}_{50}$ frequency distribution showed a best fit when the existence of two different populations was assumed. The distribution showed a bimodal curve, with some individuals clustered around a low $\mathrm{IC}_{50}(0.35$ to $1.8 \mathrm{mM})$ and others around a high $\mathrm{IC}_{50}$ ( 3 to $4 \mathrm{mM}$ ). We also observed that the bimodal distribution was essentially the same for control subjects and for patients treated with lithium. Although there was no difference between controls and patients, the variation among individuals was significant.

Lithium treatment might lead to the expression of an isoform of phosphoglucomutase that is more resistant to lithium inhibition. However, Figure 2B shows that the $\mathrm{IC}_{50}$ values of lithium-treated patients were not correlated with lithemia (correlation coefficient $=-0.27$ ). We also analyzed if $\mathrm{IC}_{50}$ values correlated with the rate of phosphoglucomutase activity and found no correlation (data not shown). Although the $\mathrm{IC}_{50}$ values represent inhibition in vitro, it is likely that phosphoglucomutase is not affected by lithium in vivo in patients with a high $\mathrm{IC}_{50}$ since lithemia was less than $1.1 \mathrm{mEq} / \mathrm{L}$ in all cases.

\section{Discussion}

Phosphoglucomutase is a key enzyme in carbohydrate metabolism, glycogen synthesis and degradation, galactose metabolism and protein glycosylation (8). Although it has not been tested if bipolar disorder is linked to any metabolic disorder regulated by phosphoglucomutase, inhibition of this enzyme by lithium would probably lead to galactosemia and poor glycogen turnover, as has been shown in yeast (8). A recent report has shown that phosphoglucomutase activity is up-regulated in leukocytes from lithium-treated patients, even though lithium inhibits phosphoglucomutase activity in vitro (10). In the present study, we determined the distribution of phosphoglucomutase activity in erythrocytes from control, lithiumtreated and carbamazepine-treated subjects, in order to determine if differences in phosphoglucomutase activity are linked to bipolar disorder. We found that patients treated with carbamazepine displayed a significant difference from lithium-treated patients activity $(747.3 \pm 27.6$ vs $879.5 \pm 35.9$ pmol mg $\mathrm{Hb}^{-1} \mathrm{~min}^{-1}$, respectively; Table 1). Csutora et al. (11) reported that phosphoglucomutase activity is enhanced in leukocytes of lithiumtreated patients compared to healthy subjects. This discrepancy might be due to the use of erythrocytes instead of leukocytes. The best way to study alterations in phosphoglucomutase activity after lithium treatment would be a time-controlled study in which blood samples could be taken from 
individuals before and after prolonged lithium medication.

Phosphoglucomutase, fructose 1,6-bisphosphatase and glycogen synthase kinase 3 are inhibited by lithium and are all related to glycogen metabolism (Figure 3). However, the role of glycogen in brain metabolism and mood disorders is not well understood. Glial cells play an important role in glycogen metabolism in the brain. Recent findings indicate that glycogen in astrocytes can support axon function under both pathological and physiological conditions, with astrocytes

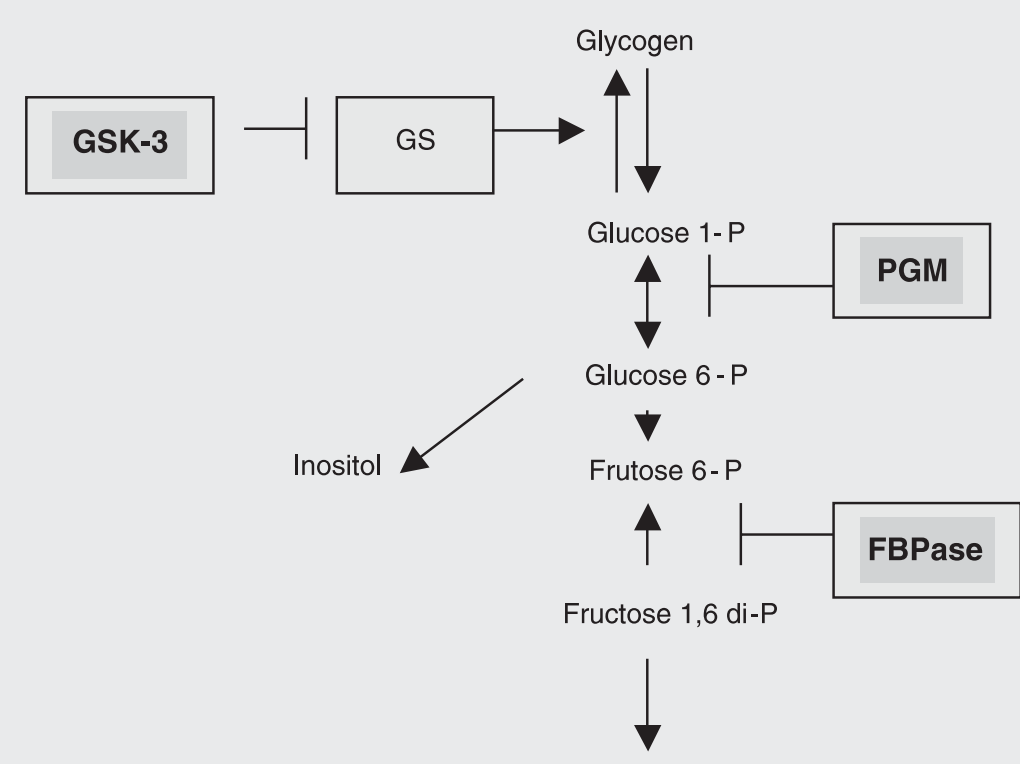

Glycolysis and respiration

Figure 3. Lithium inhibits three enzymes involved in glycogen metabolism. Depending on the energy demands of the cell, glucose 6-phosphate (glucose 6-P) can be consumed by glycolysis and respiration or stocked in the form of glycogen. Two main enzymes involved in glycogen turnover are inhibited by lithium: phosphoglucomutase (PGM), which catalyzes the reversible formation of glucose 6-P to glucose 1-phosphate (glucose 1-P) and glycogen synthase kinase 3 (GSK-3), which in the active phosphorylated form inhibits glycogen synthase (GS). Lithium also inhibits fructose-1,6-bisphosphatase (FBPase) that converts fructose-1,6-bisphosphate to fructose-6-phosphate in gluconeogenesis. Inhibition of these enzymes suggests that the therapeutic effect of lithium may be related to regulation of glucose metabolism. exporting lactate to neurons by degrading glycogen during an aglycemia insult (16). It has also been found that the number of glial cells is reduced in major depressive disorders, and bipolar patients not treated with lithium or valproate had a significant glial reduction (17). Inhibition of phosphoglucomutase and glycogen synthase kinase 3 enzymes could impair glycogen turnover. However, prolonged lithium treatment might result in increased glycogen metabolism in the brain.

An important aspect of our results is that phosphoglucomutase inhibition by lithium $\left(\mathrm{IC}_{50}\right)$ in erythrocytes showed a bimodal behavior among the subjects studied: in part of the population the $\mathrm{IC}_{50}$ was less than $1 \mathrm{mM}$, close to the therapeutic range used, while in another part the $\mathrm{IC}_{50}$ was more than $3 \mathrm{mM}$, far from the range used therapeutically. Both control and lithium-treated subjects showed a bimodal distribution, which suggests that at least two different isoforms of phosphoglucomutase are normally expressed in erythrocytes. Expression of the resistant form is not correlated to prolonged lithium treatment since the distribution of $\mathrm{IC}_{50}$ in lithiumtreated subjects was not related to lithemia (Figure 2B). If phosphoglucomutase is an important target for lithium therapy we might expect subjects with a high lithium $\mathrm{IC}_{50}$ not to be responsive. This issue must be studied further in patients undergoing lithium monotherapy.

\section{Acknowledgments}

We thank Prof. Leila Grivet for assistance with blood collection, Sônia C.F. Silva for technical assistance, and Claudio A. Masuda for helpful discussions. 


\section{References}

1. Coryell W, Solomon D, Leon AC, Akiskal HS, Keller MB, Scheftner WA, et al. Lithium discontinuation and subsequent effectiveness. Am J Psychiatry 1998; 155: 895-898.

2. Klein PS, Melton DA. A molecular mechanism for the effect of lithium on development. Proc Natl Acad Sci U S A 1996; 93: 8455-8459.

3. Kao KR, Elinson RP. The legacy of lithium effects on development. Biol Cell 1998; 90: 585-589.

4. Peters DJ, van Lookeren Campagne MM, Van Haastert PJ, Spek W, Schaap P. Lithium ions induce prestalk-associated gene expression and inhibit prespore gene expression in Dictyostelium discoideum. $J$ Cell Sci 1989; 93 (Pt 1): 205-210.

5. Stambolic V, Ruel L, Woodgett JR. Lithium inhibits glycogen synthase kinase- 3 activity and mimics wingless signalling in intact cells. Curr Biol 1996; 6: 1664-1668.

6. Hedgepeth CM, Conrad LJ, Zhang J, Huang HC, Lee VM, Klein PS Activation of the Wnt signaling pathway: a molecular mechanism for lithium action. Dev Biol 1997; 185: 82-91.

7. York JD, Ponder JW, Majerus PW. Definition of a metal-dependent/ $\mathrm{Li}(+)$-inhibited phosphomonoesterase protein family based upon a conserved three-dimensional core structure. Proc Natl Acad Sci U S A 1995; 92: 5149-5153.

8. Masuda CA, Xavier MA, Mattos KA, Galina A, Montero-Lomeli M. Phosphoglucomutase is an in vivo lithium target in yeast. $J$ Biol Chem 2001; 276: 37794-37801.

9. Nordenberg J, Kaplansky M, Beery E, Klein S, Beitner R. Effects of lithium on the activities of phosphofructokinase and phosphoglucomutase and on glucose-1,6-diphosphate levels in rat muscles, brain and liver. Biochem Pharmacol 1982; 31: 1025-1031.

10. Bro C, Regenberg B, Lagniel G, Labarre J, Montero-Lomeli M, Nielsen J. Transcriptional, proteomic, and metabolic responses to lithium in galactose-grown yeast cells. J Biol Chem 2003; 278: 32141-32149.

11. Csutora P, Karsai A, Nagy T, Vas B, Kovacs L, Rideg O, et al. Lithium induces phosphoglucomutase activity in various tissues of rats and in bipolar patients. Int J Neuropsychopharmacol 2005; 1-7.

12. American Psychiatric Association. Diagnostic and statistical manual for mental disorders - DSM-IV. 4th edn. Washington: American Psychiatric Press; 1994.

13. First MB, Spitzer RL, Gibbon M, Williams JBM. Structured clinical interview diagnostic (SCID) for DSM-IV axis I disorders-clinician version (SCID-CV). Washington: American Psychiatric Press; 1997.

14. Bergmeyer HU. Methods in enzymatic analysis. 3rd edn. Weinheim: Verlag Chemie; 1986.

15. Drabkin DL. The molecular weight of haemoglobin, its iron and nitrogen content and optical properties - their relevance in the problem of a reference standard for haemoglobin measurement. Bibl Haematol 1965; 21: 33-42.

16. Brown AM, Baltan TS, Ransom BR. Energy transfer from astrocytes to axons: the role of CNS glycogen. Neurochem Int 2004; 45: 529536.

17. Bowley MP, Drevets WC, Ongur D, Price JL. Low glial numbers in the amygdala in major depressive disorder. Biol Psychiatry 2002; 52: 404-412. 